such as homosexuals, drug abusers, and haemophiliacs there is the possibility that spread may be taking place in the heterosexual population. For this reason we consider that antenatal specimens are ideal for screening initially since this could be of additional relevance to the patient and the outcome of pregnancy. Such a policy requires national agreement and would also require an increase in laboratory resources. Nevertheless, we feel that this would be a rewarding exercise enabling us to gain valuable information and to monitor the efficacy of the government publicity campaign.

A E WRIGHT A J LJUNGGREN
A J BINT

A A CODD

R FREEMAN J SELLARS

H R INGHAM M S SPROTT

M A KNOWLES

\author{
Northern Region Consultant \\ Microbiologists Group, \\ Public Health Laboratory, \\ General Hospital,
}

Newcastle upon Tyne NE4 6BE

SIR,-Sir Richard Doll and his colleagues have been thwarted in their attempts to determine the true prevalence of infection with human immunodeficiency virus (HIV) in the United Kingdom. Currently there are 610 cases of the acquired immune deficiency syndrome (AIDS), and at least 30000 individuals are reported to be infected with HIV, of whom $30 \%$ and maybe many more will eventually develop AIDS or related disorders. Evidence suggests that heterosexual HIV infection is rare and found predominantly in intravenous drug abusers. The true position is unknown since nobody has looked at representative population samples. Professor Doll suggests that antenatal samples (among others) could be tested.

As commonly practised, antenatal screening includes haemoglobin, blood group, and antibody tests and also seeks evidence of rubella immunity, syphilis ( 1 positive in about 3000 ), and hepatitis $B$ antigen (1 positive in about 1000). HIV antibody tests could be included (the incidence of positive cases is unknown but is possibly similar).

Public education about AIDS is improving, and most pregnant women have nothing to fear from it. Each woman confirmed as HIV positive represents two patients (fetus included) and needs proper counselling; her own health may benefit from pregnancy being terminated, thus also avoiding the birth of a baby with a roughly $50 \%$ chance of being infected.

Anonymous testing is imperfect since it necessitates withholding confirmed positive results. However, if the common practice of undertaking test without prior informed consent (justified by clinical discretion) has now become unacceptable then for consistency we should inform all patients of what tests are done and why: a confirmed HIV positive result is not the only one with serious and lifethreatening consequences-consider a blood test confirming leukaemia or a biopsy indicating carcinoma. For antenatal clinics it should be ethically acceptable for simple handouts to be devised explaining the implications of tests requested and as with blood donors, for dissenting patients to be given suitable opportunity to discuss and even refuse them.

HIV infection is not restricted to even an increasing number of high risk population subgroups. Not all patients declare or even know their high risk status. Our profession should positively seek HIV infection wherever it occurs, using al resources necessary to diagnose, control, and treat it and to prevent unnecessary spread. As I have long advocated, ' routine screening for HIV should be done during pregnancy, perhaps as suggested above, even if initially in selected areas. It would help prosecute these aims, simultaneously establishing a sound epidemiological base for future developments.

Regional Blood Transfusion Centre

Regional Blood Transfus

Oxford OX3 9DU

1 Entwistle CC. Prevention of AIDS. Lancet 1985;ii:1362.

\section{Widespread use of condoms and low prevalence of sexually transmitted diseases in Danish non-drug addicts}

SIR,-Dr Kim Krogsgaard and colleagues (6 December, $p$ 1473) document the low prevalence of human immunodeficiency virus infection among a group of prostitutes studied in Copenhagen. Such research is to be encouraged as it counters widespread prejudice about prostitutes as sources of infection.

However, the study is limited because the authors investigated only women working in massage parlours and escort agencies. These may be the primary workplaces for Copenhagen prostitutes, but they represent only a small number of the workplaces generally associated with prostitution. ${ }^{2}{ }^{3}$ Because sexual practices and therefore the potential range of infection vary with the type of prostitution it would be incorrect to draw any very general conclusions from this study.

Notably lacking are any investigations into the most common infections, Chlamydia trachomatis and Neisseria gonorrhoea. ${ }^{4}$ Consequently, it is hard to find evidence for the conclusion that there is a "low prevalence of sexually transmitted diseases in Danish non-drug addict prostitutes."

The authors conclude further that the widespread use of condoms may be responsible for low rates of infection. From their figures it appears that only three of the 101 women studied practised vaginal intercourse without a condom. If the other 98 are using condoms for all vaginal intercourse we would have expected a comment on this figure, as it seems unusually high. In our experience any information about condom use requires detailed prospective records because reports of $100 \%$ condom use in a one off interview are rarely borne out in records created over a number of meetings.

Finally, nothing is said about prostitutes' other sexual relationships. In our own studies very few women report condom use with their non-paying partners (unpublished data)

\section{HELEN WARD}

SOPHIE DAY

Jefferiss Research Wing

J R W HARRIS

London W/2

SIMON BARTON

Whittington Hospital,

London $\mathrm{N} 19$

Walkowitz JR. Prostitution and Victorian sociery: women, class and the state. Cambridge: Cambridge University Press, 1980.

2 McLeod E. Women working: prostitution now. London: Croom Helm, 1982.

Perkins R, Bennett G. Being a prostitute: prostitute women and prostitute men. Sydney: George Allen and Unwin, 1985.

Barton SE, Underhill GS, Gilchrist C, et al. HTLV-III antibody in prostitutes. Lancet 1985;ii:, 1424

\section{AIDS publicity}

SIR,-Mr G B Hastings and colleagues (3 January, p 48) described shock horror tactics against the acquired immune deficiency syndrome as "unlikely to work." We believe that this statement is too sweeping and may mislead those responsible for local publicity campaigns. The "fear" approach can be a powerful weapon in public health if certain principles are observed.

Published reports on the use of fear in health education suggest that, although high levels may be counterproductive, lower levels may be highly effective. ${ }^{1}$ Marsh, commenting ${ }^{2}$ on a study of 2700 British smokers, ${ }^{3}$ found: "The most favourable attitudes, in terms of avoiding something they fear, are associated not with heart disease or lung cancer but with bronchitis.... Many of them have probably experienced it [respiratory complaints] often enough to know what it feels like".

We ourselves discovered that even high fear can be effective used in conjunction with an appeal to protect vulnerable loved ones (the two step approach). In 1985-6 the Health Education Council used a TV commercial in which a 9 year old girl was shown worrying about her smoking father's persistent cough. He finally discovered her looking up the term "lung cancer" in a dictionary. Evaluation showed that this combination of the two step approach with high fear had a powerful impact on relatively heavy smokers, a group normally difficult to motivate (NOP Market Research Ltd, reports for HEC, 1985)

Both the smoking and the AIDS campaign involve persuading people to modify pleasurable forms of behaviour to prevent serious diseases, which may not be perceived as personally threatening. High fear messages are unlikely to influence heterosexuals to change their behaviour because AIDS, like lung cancer, is perceived as too threatening to think about, and it is also perceived (rightly at present) as "very unlikely to happen to me" (Harris Research Centre, 1986).

However, low fear messages emphasising risks already personally familiar to the target group will probably be more successful. Hence the risks of herpes and gonorrhoea (but probably not cervical cancer) need to be stated to create beliefs such as, "You can catch all kinds of unpleasant infections from your partner-AIDS is only one of them."

The two step approach should also be used in appeals to the sexually active to protect their partners if they will not protect themselves. Again, AIDS should form only part of the message, to avoid the inference that the use of a condom automatically implies seropositivity. The two step approach may be particularly effective in communicating with intravenous drug users. Addicts are often careless about risks to themselves but may be more willing to take precautions to protect others. ${ }^{4}$

Publicity aimed at identifiable high risk groups such as homosexuals can probably use higher levels of fear because they are more likely to perceive AIDS as a personal threat. Evidence for this is provided by the finding that gonorrhoea in homosexual men in London fell substantially as a result of media coverage of AIDS in 1982-3, at a time when the equivalent rates among heterosexuals were rising. ${ }^{5}$

Nevertheless, we agree with $\mathrm{Mr}$ Hastings and his colleagues that the guiding principle in the design of effective communication is always to begin by finding out "where the people are at." $A$ gram of market research at the outset will always be worth many kilograms of effective prevention in the end.

Education Division,

DONALD REID

Public Affairs Division,

Health Education Council,

London WC1A IAH

Janis I, Feshbach S. Effects of fear-arousing communications fourmal of Abnormal and Social Psychology 1953;48:78-92.

2 Marsh A. Smoking and illness: what smokers really believe. Health Trends 1985;17:7-12. 